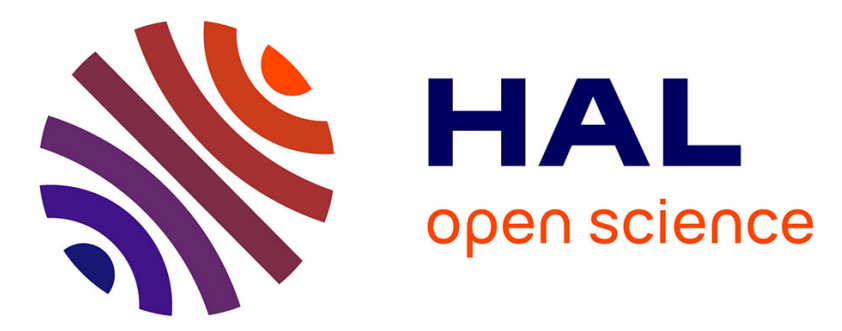

\title{
Ionospheric density perturbations recorded by DEMETER above intense thunderstorms
}

Michel Parrot, Jean-André Sauvaud, S Soula, Jean-Louis Pinçon, O van Der Velde

\section{- To cite this version:}

Michel Parrot, Jean-André Sauvaud, S Soula, Jean-Louis Pinçon, O van Der Velde. Ionospheric density perturbations recorded by DEMETER above intense thunderstorms. Journal of Geophysical Research Space Physics, 2013, 118, pp.5169-5176. 10.1002/jgra.50460 . insu-01179319

\section{HAL Id: insu-01179319 \\ https://hal-insu.archives-ouvertes.fr/insu-01179319}

Submitted on 22 Jul 2015

HAL is a multi-disciplinary open access archive for the deposit and dissemination of scientific research documents, whether they are published or not. The documents may come from teaching and research institutions in France or abroad, or from public or private research centers.
L'archive ouverte pluridisciplinaire HAL, est destinée au dépôt et à la diffusion de documents scientifiques de niveau recherche, publiés ou non, émanant des établissements d'enseignement et de recherche français ou étrangers, des laboratoires publics ou privés. 


\title{
Ionospheric density perturbations recorded by DEMETER above intense thunderstorms
}

\author{
M. Parrot, ${ }^{1}$ J. A. Sauvaud, ${ }^{2}$ S. Soula, ${ }^{3}$ J. L. Pinçon, ${ }^{1}$ and O. van der Velde ${ }^{4}$ \\ Received 15 March 2013; revised 17 July 2013; accepted 18 July 2013; published 8 August 2013.
}

[1] DEMETER (Detection of Electromagnetic Emissions Transmitted From Earthquake Regions) was a three-axis stabilized Earth-pointing spacecraft launched on 29 June 2004 into a low-altitude $(710 \mathrm{~km})$ polar and circular orbit that was subsequently lowered to $650 \mathrm{~km}$ until the end of the mission in December 2010. DEMETER measured electromagnetic waves all around the Earth, except in the auroral zones (invariant latitude $>65^{\circ}$ ). The frequency range for the electric field was from DC up to $3.5 \mathrm{MHz}$, and for the magnetic field, it was from a few hertz up to $20 \mathrm{kHz}$. At its altitude, the phenomena observed on the $E$ field and $B$ field spectrograms recorded during nighttime by the satellite in the very low frequency range are mainly dominated by whistlers. In a first step, the more intense whistlers have been searched. They correspond to the most powerful lightning strokes occurring below DEMETER. Then, it is shown that this intense lightning activity is able to perturb the electron and ion densities at the satellite altitude (up to 133\%) during nighttime. These intense lightning strokes are generally associated with transient luminous events, and one event with many sprites recorded on 17 November 2006 above Europe is reported. Examining the charged particle precipitation, it is shown that this density enhancement in the high ionosphere can be related to the energetic particle precipitation induced by the strong whistlers emitted during a long-duration thunderstorm activity at the same location.

Citation: Parrot, M., J. A. Sauvaud, S. Soula, J. L. Pinçon, and O. van der Velde (2013), Ionospheric density perturbations recorded by DEMETER above intense thunderstorms, J. Geophys. Res. Space Physics, 118, 5169-5176, doi:10.1002/jgra.50460.

\section{Introduction}

[2] Perturbation of the lower ionosphere by thunderstorm activity has been known for a long time. Checking the amplitude of long-distance subionospheric very low frequency (VLF) transmitters, Helliwell et al. [1973] were the first to report nighttime changes associated with whistlers. The phenomenon called "Trimpi effect" was explained by the precipitation of energetic electrons into the $D$ region due to these whistlers. At the end, this changes the properties of the Earth-ionosphere waveguide. Later on, many works have been done to show the ionization in the bottom of the ionosphere [see, e.g., Inan and Carpenter, 1987; Inan et al., 1993; Pasko et al., 1998; Strangeways, 1999; Farges et al., 2007; Inan et al., 2010]. Using a model, Inan et al. [1991] were the first to calculate ionospheric density changes at $90-95 \mathrm{~km}$ altitude by individual lightning discharges, through secondary ionization by heated electrons. Rodger

\footnotetext{
${ }^{1}$ LPC2E/CNRS, Orléans, France.

${ }^{2}$ IRAP, Toulouse, France.

${ }^{3}$ Laboratoire d'Aérologie, OMP, Toulouse, France.

${ }^{4}$ Electrical Engineering Department, Technological University of Catalonia, Terrassa, Spain.

Corresponding author: M. Parrot, LPC2E/CNRS, 3A Avenue de la Recherche, FR-45071 Orléans CEDEX 2, France. (mparrot@cnrs-orleans.fr)

(C)2013. American Geophysical Union. All Rights Reserved. 2169-9380/13/10.1002/jgra.50460
}

et al. [2001] used lightning data detected over the U.S. with a simulation code to show that successive intense lightningelectromagnetic pulse (EMP) events could induce largescale changes in the nighttime lower ionosphere. They have shown that these strong lightning-EMP events can lead to significant ( $100 \%$ or even greater) increases in the electron density of the lower ionosphere during nighttime, with the largest increases at $90 \mathrm{~km}$ altitude. They also indicated that the time required to produce large-scale changes in ionospheric electron density above an active thunderstorm may be related to the start of a red sprite activity.

[3] Recently, modification of the global atmospheric circuit by intense thunderstorms has been reviewed by Rycroft and Harrison [2012], and Füllekrug et al. [2013] have published a report dealing with ionization and electrical discharge processes, observations of transient luminous events, electromagnetic emissions, energetic charged particles, and their impact on the Earth's atmosphere.

[4] The aim of this paper is to use data from the low-altitude satellite DEMETER (Detection of Electromagnetic Emissions Transmitted From Earthquake Regions) to show that ionization processes occur also in the upper ionosphere above intense thunderstorms. The DEMETER payload, the TLE (transient luminous event) detector, and the ground-based lightning network are briefly described in section 2 . In section 3 , some events with high wave intensity and simultaneous ionospheric density perturbations are shown. A dramatic event where lightning stroke characteristics are known and where many 


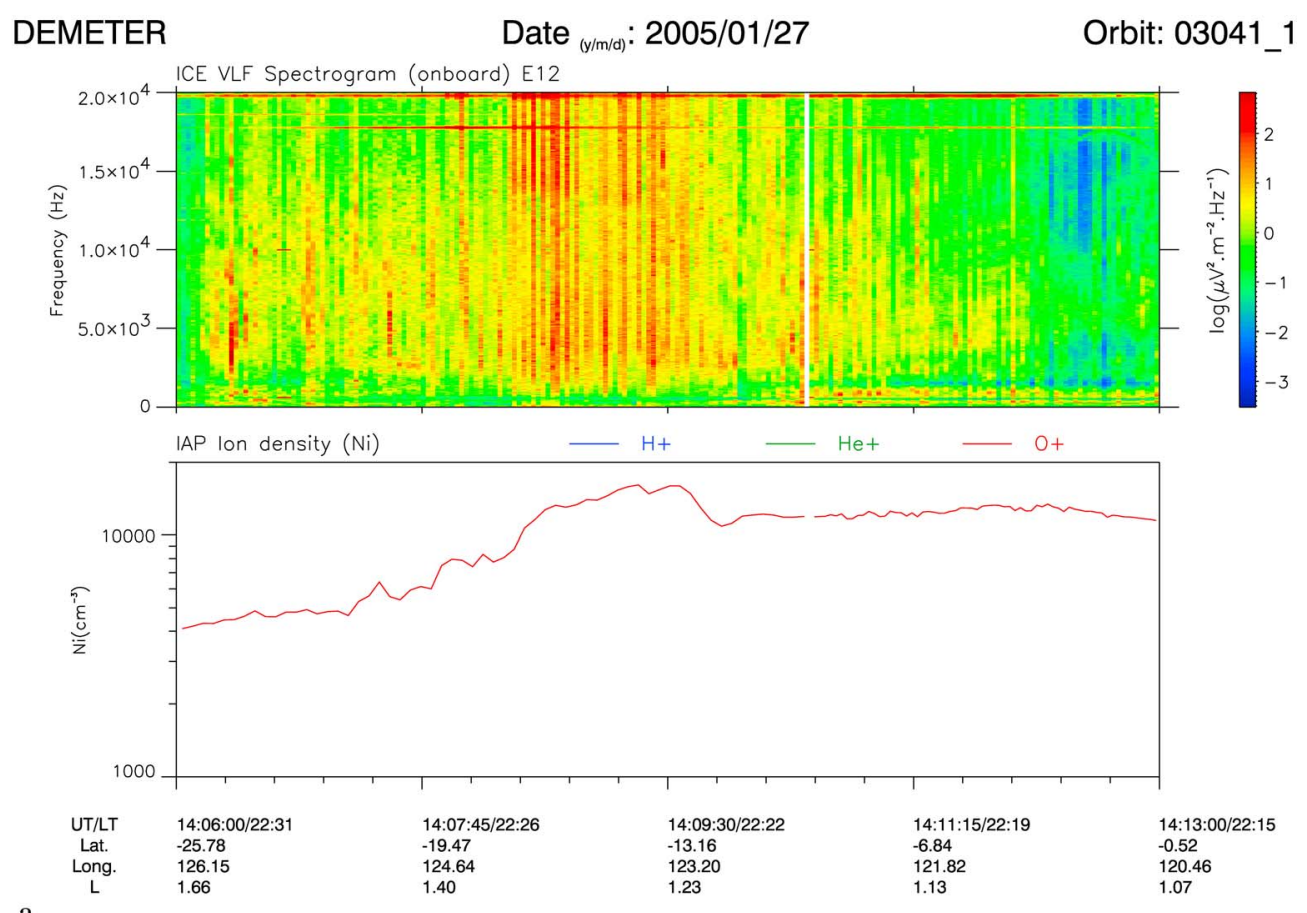

$\mathrm{a}$

DEMETER Date ${ }_{(\mathrm{y} / \mathrm{m} / \mathrm{d})}: 2005 / 07 / 21 \quad$ Orbit: 05583_1
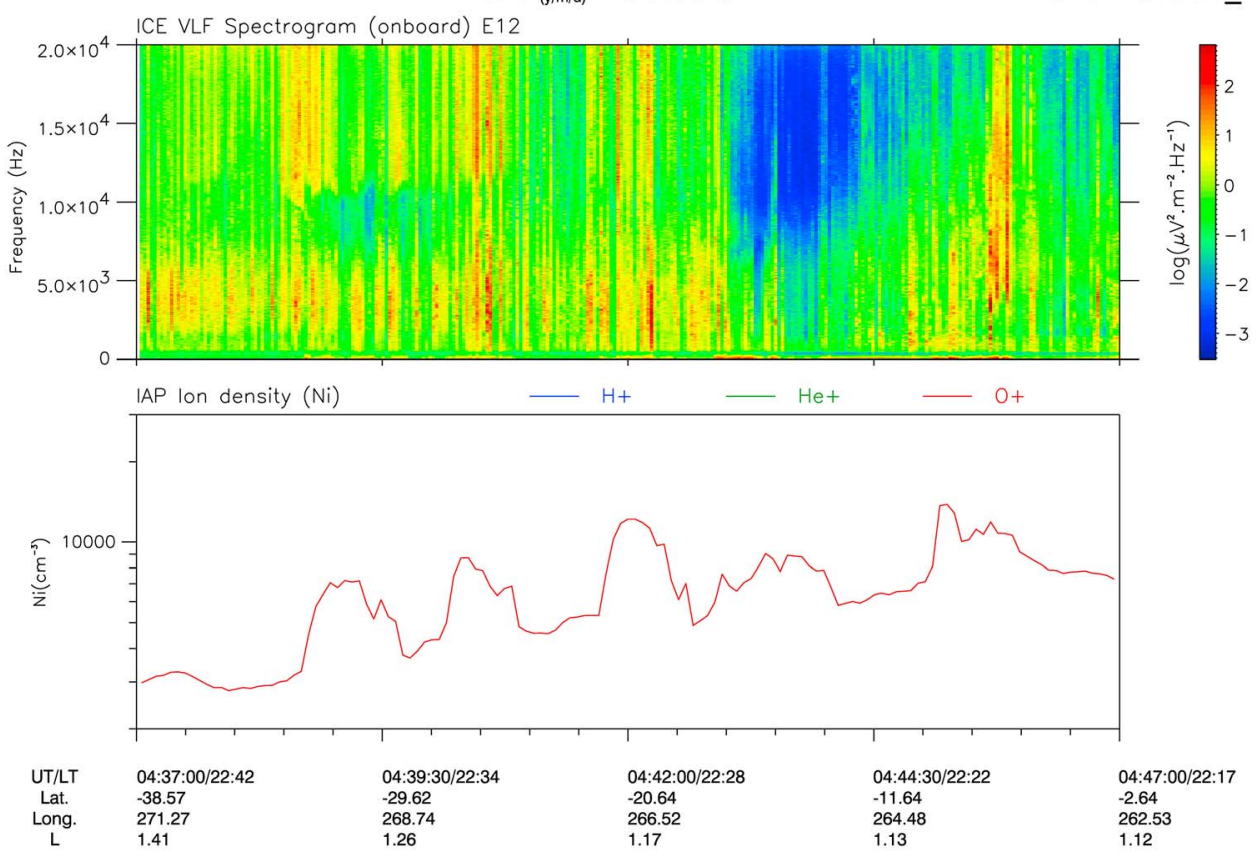

b

Figure 1. (a) Data recorded on 27 January 2005 between 14:06:00 and 14:13:00 UT. (b) Data recorded on 21 July 2005 between 04:37:00 and 04:47:00 UT. (c) Data recorded on 21 January 2006 between 12:46:00 and 12:53:00 UT. (d) Data recorded on 7 January 2006 between 11:59:00 and 12:07:00 UT. The top panels in Figures 1a-1d represent the spectrogram of an electric field component from 0 to $20 \mathrm{kHz}$. The intensity is color-coded according to the color scale on the right. The bottom panels in Figures 1a-1d represent the variation of the $\mathrm{O}^{+}$ion density (the densities of the other ions are much lower). The information at the bottom of Figures $1 \mathrm{a}-1 \mathrm{~d}$ is related to the universal time, the local time, the geographic latitude and longitude, and the McIlwain parameter $L$. 

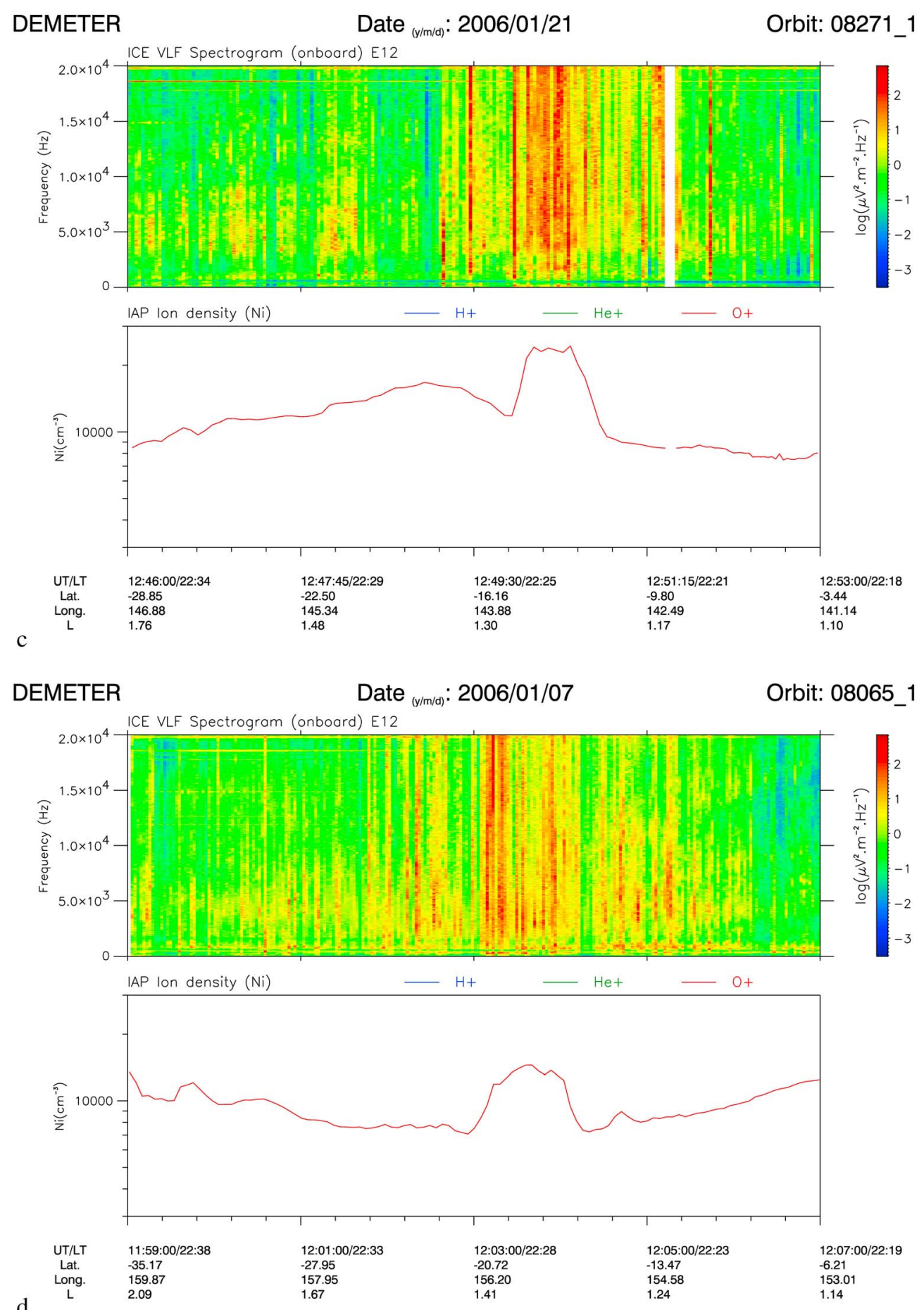

Figure 1. (continued)

sprites have been recorded is presented in section 4 . Discussion and conclusions are provided in sections 5 and 6 , respectively.

\section{The Experiments}

\subsection{The DEMETER Satellite}

[5] DEMETER was a low-altitude satellite $(710 \mathrm{~km})$ launched in June 2004 onto a polar and circular orbit which measured electromagnetic waves and plasma parameters all around the globe, except in the auroral zones and polar cap [Parrot, 2006]. The altitude of the satellite was decreased to $660 \mathrm{~km}$ in December 2005. The satellite's science mission has come to an end in December 2010. Due to technical reasons, data were only recorded at invariant latitudes less than $65^{\circ}$. The orbit of DEMETER was nearly Sun synchronous, and the upgoing half-orbits correspond to nighttime (22:30 local time (LT)), whereas the downgoing half-orbits correspond to daytime (10:30 LT). The very low frequency (VLF) range of the electric field experiment named ICE (Instrument 
Table 1. List of Sprite-Producing Lightning Strokes Recorded on 17 November 2006 in the Same Area Just Before the Pass of the Satellite ${ }^{\mathrm{a}}$

\begin{tabular}{lccc}
\hline Hour (UT) & Longitude & Latitude & Current (kA) \\
\hline $19: 29: 21.7119217$ & 4.851 & 44.1049 & 77.3 \\
$19: 44: 51.3264650$ & 4.7853 & 44.333 & 83.2 \\
$19: 50: 17.0137949$ & 4.7807 & 44.378 & 104.5 \\
$19: 50: 17.1541844$ & 4.6716 & 44.6832 & 53.4 \\
$19: 57: 29.4213629$ & 4.8244 & 44.6825 & 52.9 \\
$20: 01: 03.6943259$ & 4.8773 & 44.1881 & 54.6 \\
$20: 03: 43.4388403$ & 4.9819 & 44.7632 & 116.8 \\
$20: 07: 56.7688636$ & 4.9701 & 44.4604 & 76.5 \\
$20: 05: 56.9085465$ & 4.9031 & 44.6584 & 37.8 \\
$20: 11: 01.9779061$ & 4.6365 & 44.4837 & 55.5 \\
$20: 15: 52.9067169$ & 4.9236 & 44.5048 & 107.2 \\
$20: 15: 52.9539847$ & 4.7719 & 44.6222 & 112.2 \\
$20: 21: 43.7457350$ & 4.7309 & 44.467 & 82.1 \\
$20: 25: 57.5093498$ & 4.9657 & 44.8503 & 165.8 \\
$20: 34: 05.6411427$ & 5.2921 & 44.0880 & 19.0 \\
$20: 42: 05.6411427$ & 5.0709 & 44.4101 & 76.7 \\
$20: 52: 42.2526533$ & 5.3471 & 44.58 & 109.2 \\
\hline
\end{tabular}

${ }^{\mathrm{a}}$ The columns display the hour, the geographic longitude and latitude, and the peak current in kiloamperes. Each of these lightning strokes triggered a sprite event. The sprite event triggered by the last one is shown in Figure 4.

Champ Electrique) is from 0 to $20 \mathrm{kHz}$. There are two scientific modes, namely, survey mode and burst mode, when the satellite is above regions of interest. The spectrum of one electric component is onboard computed in the VLF range during the two modes. The frequency resolution is $19.5 \mathrm{~Hz}$, and the time resolution is $2.048 \mathrm{~s}$. During the burst mode, waveforms of the same electric field component are recorded up to $20 \mathrm{kHz}$ in addition to the spectrum. The burst mode allows the performance of a spectral analysis with higher time and frequency resolution. In the survey mode, the power spectra are the only information available. Details of the electric field experiment ICE are given by Berthelier et al. [2006a]. In this paper, the onboard-computed VLF spectra during nighttime will be used.

[6] To study the variations of the ion density, the payload of DEMETER included a plasma analyzer instrument named IAP (Instrument Analyseur de Plasma) which gives ion density with a $4 \mathrm{~s}$ time resolution. Details of the IAP experiment can be found in Berthelier et al. [2006b]. A solid-state energetic particle detector IDP (Instrument Détecteur de Particules) measured high-energy electrons and protons in the drift loss cone (or just outside) with energies from $70 \mathrm{keV}$ to $2.34 \mathrm{MeV}$ every $4 \mathrm{~s}$ in survey mode and $1 \mathrm{~s}$ in burst mode [Sauvaud et al., 2006]. The energy channel resolution depends on the operational mode of the satellite, being either $17.8 \mathrm{keV}$ in survey mode or $8.9 \mathrm{keV}$ in burst mode.

\subsection{Optical Observations}

[7] During the specific sequence of observations shown in this paper, the optical camera system was located at Observatoire Midi-Pyrénées, Toulouse $\left(43.56^{\circ} \mathrm{N}, 1.48^{\circ} \mathrm{E}\right.$; $\sim 150 \mathrm{~m})$. It includes one low-light and high-resolution charge-coupled device camera (Watec 902H) equipped with a $16 \mathrm{~mm} f / 1.4$ lens characterized by a $23^{\circ}$ field of view, as described in Soula et al. [2009]. The time resolution is $20 \mathrm{~ms}$. The GPS time collected via an antenna is inserted in the images through the use of a video time inserter device from PFD Systems (KIWI OSD).

\subsection{The Ground-Based Lightning Network}

[8] The lightning detection network run by Météorage provides data for the identification of location, polarity, peak current value, number of strokes, and timing of cloud-to-ground (CG) strokes on French territory. Part of the European Cooperation for Lightning Detection (EUCLID), it includes 18 sensors which detect radiation in the LF range produced by the return strokes of CG flashes. These sensors use both magnetic direction finding and time-of-arrival techniques to determine the location of $\mathrm{CG}$ strokes [Cummins et al., 1998]. The detection efficiency is $\sim 90 \%$ inland and close to the coastline. In order to identify the CG flashes, consecutive strokes are associated if they occur within $5 \mathrm{~km}$ of the first stroke and within $0.5 \mathrm{~s}$ from the previous stroke.

\section{Examples of Ionospheric Perturbations}

[9] Previous studies with the DEMETER data have shown that VLF wave activity is dominated by thunderstorm activity [Parrot et al., 2008; Němec et al., 2010; Colman and Starks, 2013]. Fiser et al. [2010] demonstrated that the intensity of the whistlers observed at the altitude of the satellite is directly proportional to the current of their parent lightning strokes. Then, in order to have data recorded during powerful thunderstorms, VLF electric field spectrograms with a high intensity have been selected during nighttime. It must be also noted that intense whistlers are a good indication of the occurrence of sprites [Reising et al., 1999]. In a second step, the variation of the ion density has been examined during these periods. Examples are shown in Figure 1.

[10] In Figure 1a, data have been recorded on 27 January 2005 between 14:06:00 and 14:13:00 universal time (UT)

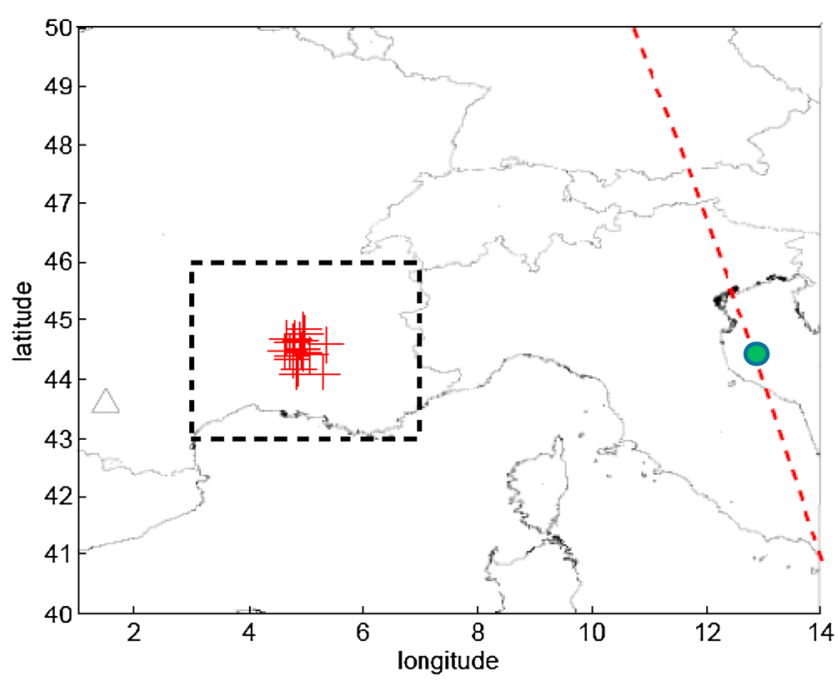

Figure 2. A map showing the orbit of the satellite (red dashed line), the observation point where the camera was located (triangle), and the locations of the lightning strokes corresponding to the sprites (red crosses). The green spot indicates the position of the satellite at the time of the sprite shown in Figure 4. The frame delimits the positions of all the lightning strokes shown in Figure 3. 


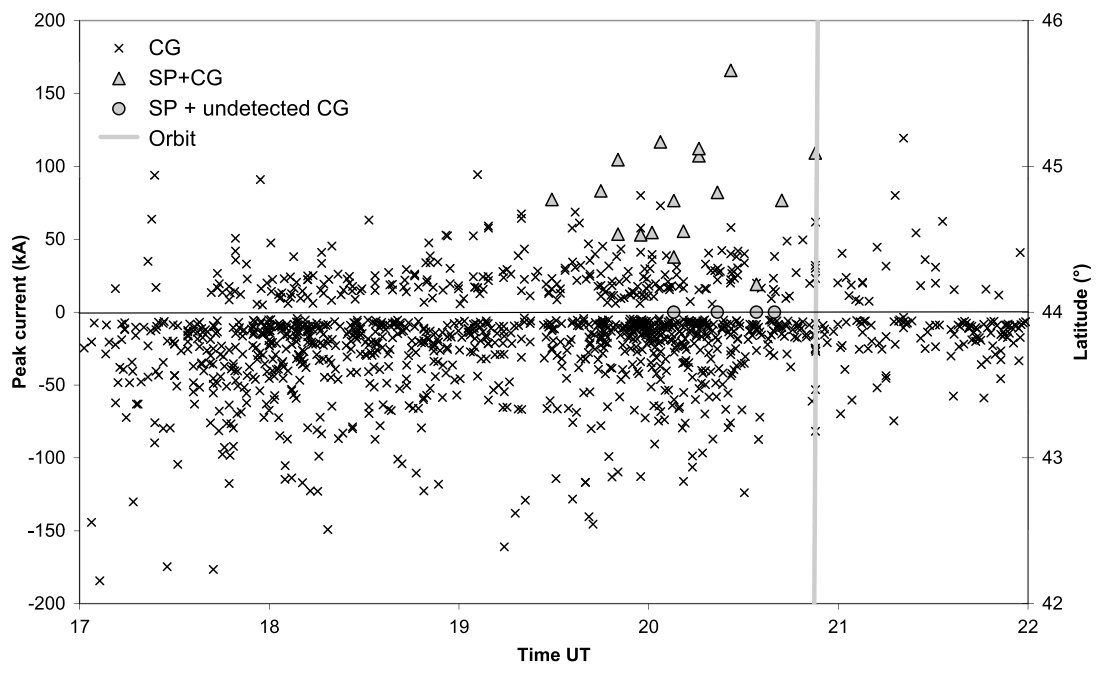

Figure 3. Evolution of the CG lightning activity in the frame shown in Figure 2. The crosses indicate the peak currents of the lightning strokes as a function of time. The triangles are related to the peak currents of the parent lightning strokes of the sprites (their characteristics are given in Table 1). The circles indicate sprite occurrences without any CG flash detected. The grey line shows the DEMETER orbit as a function of latitude shown on the right scale.

in the south hemisphere (longitude $=\sim 123^{\circ}$; latitude between $-13^{\circ}$ and $-20^{\circ}$ ). In the top panel, the spectrogram displays vertical lines which are the whistlers due to the lightning strokes. The horizontal lines are due to VLF transmitters. It can be seen that at the time where the whistlers are numerous and have a high intensity, there is an increase in the $\mathrm{O}^{+}$ion density. At the altitude of DEMETER, the $\mathrm{O}^{+}$ions are the majority. The electron density given by a different instrument has a similar variation (not shown). In this event, the whistlers are $0^{+}$whistlers (i.e., upgoing fractional hop whistlers) [Smith and Angerami, 1968], i.e., the corresponding lightning strokes occur in the same hemisphere below the satellite and the whistlers cross the ionosphere to reach the satellite.

[11] Data recorded on 21 July 2005 between 04:37:00 and 04:47:00 UT in the south hemisphere are displayed in Figure $1 \mathrm{~b}$ (longitude $=265^{\circ}$; latitude between $-20^{\circ}$ and $-30^{\circ}$ ). As we are in July, it is summer in the north, and it means that the whistlers are supposed to come from the opposite hemisphere. This is confirmed by their high dispersion values (not shown). It is shown that there are several bursts of intense whistlers and that each of them corresponds to an increase in the ionospheric density. Figure 1c shows data recorded on 21 January 2006 between 12:46:00 and 12:53:00 UT (longitude $=140^{\circ}-145^{\circ}$; latitude $=-10^{\circ}$ ) in the south hemisphere during summer time. Then, $0^{+}$whistlers dominate. Finally, Figure 1d displays data recorded on 7 January 2006 between 11:59:00 and 12:07:00 UT (longitude $=155^{\circ}$; latitude $=-20^{\circ}$ ). Intense and numerous $0^{+}$whistlers can be observed at the same time as density increase.

[12] The percentage of density increases shown in the bottom panels in Figure 1 is rather important. It covers a range from $47 \%$ (Figure 1a) up to $133 \%$ (Figure 1b). Many cases at different locations around the Earth have been shown, but information concerning the lightning strokes and the thunderstorm characteristics is not available. Another event with full auxiliary data is now presented in the next section.

\section{Sprite Events Recorded on 17 November 2006}

[13] On 17 November 2006, there was an intense winter thunderstorm in the south of France during which sprites have been recorded from Toulouse (see section 2.2). From about 19:30 UT and for a duration of about $80 \mathrm{~min}$, a total of 17 videos, including sprite events, were recorded, 13 with one sprite event and 4 with two sprite events. Thus, a total of 21 sprite events were recorded. Ground-based lightning data show that for 17 out of the 21 events, a positive lightning stroke was detected a few milliseconds earlier. Their characteristics are listed in Table 1, and Figure 2 indicates their location with red crosses. The peak current of the lightning strokes recorded in the boxed area shown in Figure 2 is

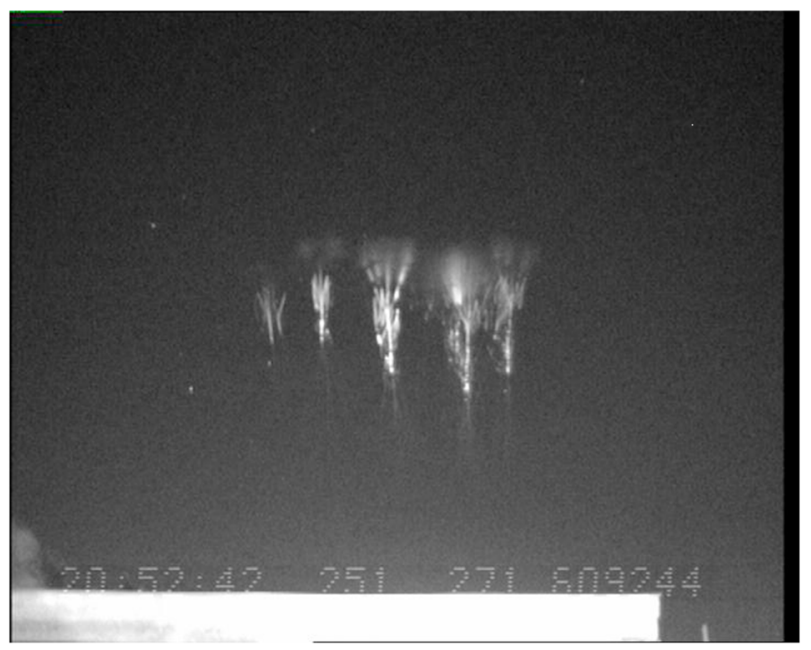

Figure 4. A frame (20 ms) displaying a carrot sprite event recorded on 17 November 2006 at 20:52:42 UT. The location of this event is given in Figure 2. The characteristics of the parent lightning stroke are given in the last line in Table 1. 


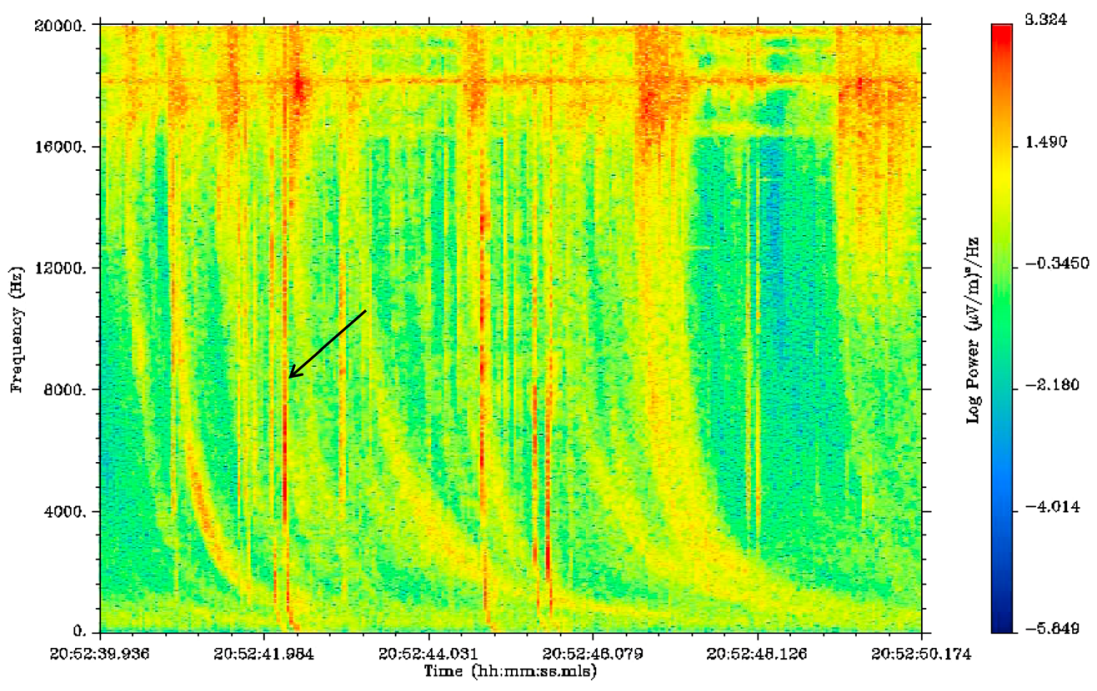

Figure 5. Detailed spectrogram $(10 \mathrm{~s})$ of the electric field recorded by DEMETER at the time of the sprite shown in Figure 2. The frequency is up to $20 \mathrm{kHz}$, and the wave intensity is color-coded according to the color scale on the right. The arrow indicates the upgoing fractional hop whistler which corresponds to the sprite.

plotted in Figure 3 as a function of time. The peak current of the 17 sprite-producing strokes is indicated with triangle symbols, and it ranges between 19 and $165.8 \mathrm{kA}$. Some of the 21 sprites were spectacular, such as that displayed in Figure 4 and registered at 20:52:42 UT. This sprite was triggered by a + CG lightning stroke of $109.2 \mathrm{kA}$.

[14] The DEMETER position relative to this lightning stroke is indicated in Figure 2 with a green spot. The parent stroke was missed by the detection system in four cases of sprite that are indicated by circles in Figure 3 (SP + undetected CG in the legend). The remarkable point is that for most of the lightning strokes with a large peak current (> $75 \mathrm{kA})$ produced after 19:30 UT, a sprite event was recorded. It means that during a period of about $1 \mathrm{~h}$ and $20 \mathrm{~min}$, several spectacular sprites occurred at nearly the same place just before the arrival of the satellite.

[15] As the experiments were in burst mode during this thunderstorm, the detailed spectrogram of the electric field at the time of the sprite shown in Figure 4 is displayed in Figure 5. The corresponding upgoing fractional hop whistler with a low dispersion is indicated by an arrow. The spectrogram recorded between 20:49:30 and 20:54:30

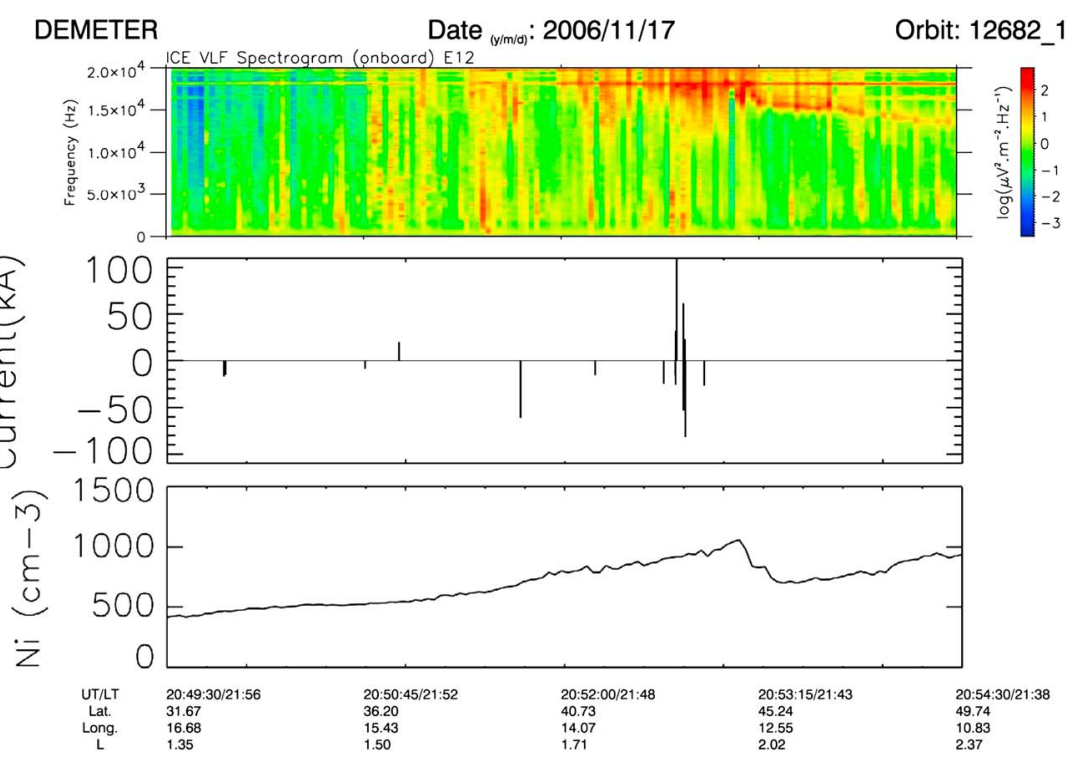

Figure 6. (top) Electric field spectrogram recorded on 17 November 2006 between 20:49:30 and 20:54:30 UT. The frequency is up to $20 \mathrm{kHz}$, and the wave intensity is color-coded according to the color scale on the right. (middle) Lightning strokes and their current occurring in the rectangular area in Figure 2. (bottom) Total ion density recorded during the same time. The information at the bottom of the figure is related to the universal time, the local time, the geographic latitude and longitude, and the McIlwain parameter $L$. 


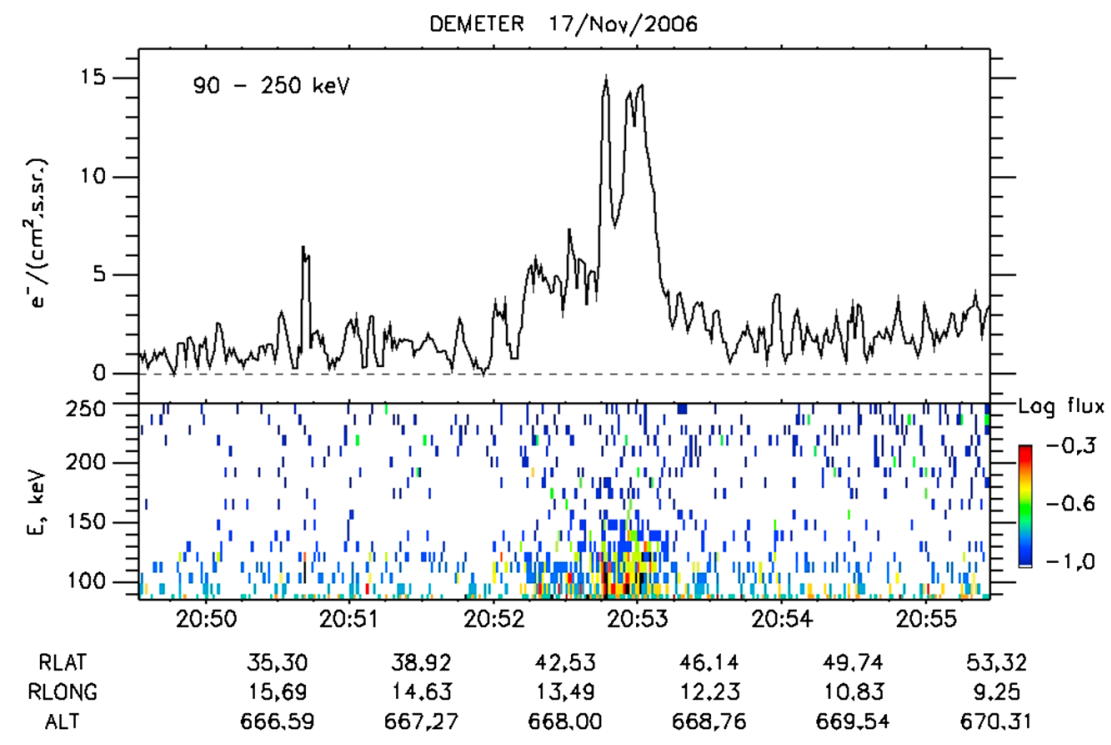

Figure 7. Energy flux recorded by DEMETER at the time of Figure 6 (when the sprite shown in Figure 4 is observed). (bottom) The energy flux from 90 up to $250 \mathrm{keV}$ as a function of the time between 20:49:30 and 20:55:30 UT. It is color-coded according to the color scale on the right. (top) The integrated flux between 90 and $250 \mathrm{keV}$. The parameters below the panels are the time in UT, the latitude, the longitude, and the altitude.

UT (it corresponds to a part of the orbit shown in Figure 2) is plotted in the top panel in Figure 6, whereas the occurrence of the lightning strokes seen by the ground network is displayed in the middle panel. The corresponding density variation is plotted in the bottom panel in Figure 6. It is the total ion density, and a variation can be seen at the time of the whistlers. This ion density reaches a maximum just after the time of the intense parent lightning of the sprite shown in Figure 4.

\section{Discussion}

[16] The only possibility to explain this increase in ionization at the altitude of the satellite above intense thunderstorms is that it is due to particle precipitation induced by the lightning strokes. In the past, it has been shown on board a rocket by Rycroft [1973] and on board satellites by Voss et al. [1984, 1998] that cyclotron-resonant loss of trapped electrons is directly associated to whistlers. In relation to DEMETER data, Inan et al. [2007] reported short bursts of lightning-induced electron precipitation simultaneously with upgoing whistlers, and Gemelos et al. [2009] showed a seasonal dependence of energetic electron precipitation above the U.S. which is attributed to the increase in the lightning activity during summer.

[17] Concerning the sprite event in Figure 4, Figure 2 shows that DEMETER is well located at the east of the thunderstorm, which means that it is a favorable situation to register energetic electron precipitation. The particle data recorded at the time of this event are shown in Figure 7. The bottom panel is related to the energy flux between 90 and $250 \mathrm{keV}$ as a function of time, and the top panel presents the integrated flux in the same energy range. It can be seen that there is a residual particle precipitation starting at 20:52:00 UT, with a large increase in the flux just after 20:52:42 UT, the time of the intense lightning stroke of 109.2 kA. Then, it is likely that the observed increase in the ion density at the altitude of the satellite is due to the particle precipitation induced by strong lightning strokes. This mechanism is also valid for density increase in a magnetically conjugate area of a thunderstorm activity (Figure 1b).

\section{Conclusions}

[18] Previous works have shown that thunderstorm activities are able to perturb the lower ionosphere. It is shown here that during nighttime, this perturbation extends to higher altitudes, particularly when TLEs are present. It means that there is a column of ionization above areas with a strong thunderstorm activity which affects the complete ionosphere. This is due to the lightning-induced electron precipitation. The DEMETER IDP detector only detects electrons with energy higher than $90 \mathrm{keV}$. However, data published by Voss et al. [1998] have shown that lightning strokes are also associated with the precipitation at lower energies, i.e., $45 \mathrm{keV}$.

[19] Though the penetration altitude is in the altitude range of 80-100 km [see Blelly and Alcaydé, 2007, Figure 8.2], these particles begin to ionize neutrals at altitudes where the neutral density is high enough, typically up to 500$600 \mathrm{~km}$ (P.-L. Blelly, personal communication, 2013). Beside this primary production, the energy deposition in the thermal electron gas results in heating of the plasma that may drive to a vertical motion associated to the polarization electric field. The delay between the heating and the transport increases with altitude: a few minutes above the F2 peak and up to an hour at $1500 \mathrm{~km}$ [Blelly et al., 1996]. Both effects lead to the enhancement of the electron and ion concentrations observed at $650 \mathrm{~km}$. Preliminary simulations performed with the new interhemispheric TRANSCAR model show that the observed $\mathrm{O}^{+}$density increase is well reproduced (P.-L. Blelly, personal communication, 2013). A detailed study of the ionospheric effects of the lightningassociated electron precipitation is underway. 
[20] The perturbation of the density covers a large area. Concerning the 17 November 2006 event, the distance between the satellite and the lightning stroke at 20:52:42 UT is on the order of $610 \mathrm{~km}$. This can be compared with the extension of the electron precipitation patches observed by Clilverd et al. [2002] at the bottom of the ionosphere. They analyzed Trimpi signatures in subionospheric VLF signals of U.S. transmitters, and they found that the patch dimensions are large, i.e., $(1500 \mathrm{~km} \times 600 \mathrm{~km})$, with the longer axis orientated east-west.

[21] The rate of the density increase (up to more than $100 \%$ ) at the satellite altitude is in agreement with the rate of the density increase which is observed at the bottom of the ionosphere by Rodger et al. [2001].

[22] This 17 November 2006 event, when a lot of sprites are observed at the same place in a short time after many powerful lightning strokes, is also a confirmation of the work of Pasko et al. [1997], who have shown that the thunderstorm electromagnetic activity can locally change the conductivity of the lower ionosphere and then is likely to favor the necessary conditions to produce sprites. An increase in ionization can lead to a feedback mechanism and to the occurrence of more and more sprites.

[23] Acknowledgments. This work was supported by the Centre National d'Etudes Spatiales. It is based on observations with the electric field experiment ICE and with the ion analyzer IAP embarked on DEMETER. The authors thank J. J. Berthelier, the Principal Investigator of ICE and IAP, for the use of the data. They thank Météorage for providing the data on the CG lightning flashes. They are also indebted to P.-L. Blelly (IRAP, Toulouse) for helpful explanations about the mechanism of the ionospheric density perturbation.

[24] Robert Lysak thanks the reviewers for their assistance in evaluating this paper.

\section{References}

Berthelier, J. J., et al. (2006a), ICE, the electric field experiment on DEMETER, Planet. Space Sci., 54, 456-471.

Berthelier, J. J., M. Godefroy, F. Leblanc, E. Seran, D. Peschard, P. Gilbert, and J. Artru (2006b), IAP, the thermal plasma analyzer on DEMETER, Planet. Space Sci., 54, 487-501.

Blelly, P.-L., and D. Alcaydé (2007), Ionosphere, in Handbook of Solar-Terrestrial Environment, edited by Y. Kamide and A. Chian, pp. 189-220, Springer, Berlin.

Blelly, P.-L., A. Robineau, and D. Alcaydé (1996), Numerical modelling of sporadic ions outflow events above EISCAT, J. Atmos. Terr. Phys., 58, 273-285.

Clilverd, M. A., D. Nunn, S. J. Lev-Tov, U. S. Inan, R. L. Dowden, C. J. Rodger, and A. J. Smith (2002), Determining the size of lightning-induced electron precipitation patches, J. Geophys. Res., 107(A8), 1168, doi:10.1029/2001JA000301.

Colman, J. J., and M. J. Starks (2013), VLF wave intensity in the plasmasphere due to tropospheric lightning, J. Geophys. Res. Space Physics, 118, doi:10.1002/jgra.50217.

Cummins, K. L., M. J. Murphy, E. A. Bardo, W. L. Hiscox, R. B. Pyle, and A. E. Pifer (1998), A combined TOA/MDF technology upgrade of the U. S. National Lightning Detection Network, J. Geophys. Res., 103, 9035-9044.

Farges, T., E. Blanc, and M. Tanguy (2007), Experimental evidence of $D$ region heating by lightning-induced electromagnetic pulses on MF radio links, J. Geophys. Res., 112, A10302, doi:10.1029/2007JA012285.
Fiser, J., J. Chum, G. Diendorfer, M. Parrot, and O. Santolik (2010), Whistler intensities above thunderstorms, Ann. Geophys., 28, 37-46.

Füllekrug, M., et al. (2013), Energetic charged particles above thunderclouds, Surv. Geophys., 34, 1-41, doi:10.1007/s10712-012-9205-z.

Gemelos, E. S., U. S. Inan, M. Walt, M. Parrot, and J. A. Sauvaud (2009), Seasonal dependence of energetic electron precipitation: Evidence for a global role of lightning, Geophys. Res. Lett., 36, L21107, doi:10.1029/ 2009 GL040396.

Helliwell, R. A., J. P. Katsufrakis, and M. L. Trimpi (1973), Whistlerinduced amplitude perturbations in VLF propagation, J. Geophys. Res., 78, 4679-4688.

Inan, U. S., and D. L. Carpenter (1987), Lightning-induced electron precipitation events observed at $\mathrm{L}$ approximately 2.4 as phase and amplitude perturbations on subionospheric VLF signals, J. Geophys. Res., 92, 3293-3303.

Inan, U. S., T. F. Bell, and J. V. Rodriguez (1991), Heating and ionization of the lower ionosphere by lightning, Geophys. Res. Lett., 18, 705-708.

Inan, U. S., J. V. Rodriguez, and V. P. Idone (1993), VLF signatures of lightning-induced heating and ionization of the nighttime $D$ region, Geophys. Res. Lett., 20, 2355-2358.

Inan, U. S., D. Piddyachiy, W. B. Peter, J. A. Sauvaud, and M. Parrot (2007), DEMETER satellite observations of lightning-induced electron precipitation, Geophys. Res. Lett., 34, L07103, doi:10.1029/2006GL029238.

Inan, U. S., S. A. Cummer, and R. A. Marshall (2010), A survey of ELF and VLF research on lightning-ionosphere interactions and causative discharges, J. Geophys. Res., 115, A00E36, doi:10.1029/2009JA014775.

Němec, F., O. Santolík, M. Parrot, and C. J. Rodger (2010), Relationship between median intensities of electromagnetic emissions in the VLF range and lightning activity, J. Geophys. Res., 115, A08315, doi:10.1029/ 2010JA015296.

Parrot, M. (Ed) (2006), First results of the DEMETER micro-satellite, Planet. Space Sci., 54(5), 411-557.

Parrot, M., J. J. Berthelier, J. P. Lebreton, R. Treumann, and J. L. Rauch (2008), DEMETER observations of EM emissions related to thunderstorms, Space Sci. Rev., 137, 511-519, doi:10.1007/s11214-008-9347-y.

Pasko, V. P., U. S. Inan, T. F. Bell, and Y. N. Taranenko (1997), Sprites produced by quasi-electrostatic heating and ionization in the lower ionosphere, J. Geophys. Res., 102, 4529-4561, doi:10.1029/96JA03528.

Pasko, V. P., U. S. Inan, and T. F. Bell (1998), Ionospheric effects due to electrostatic thundercloud fields, J. Atmos. Sol. Terr. Phys., 60, 863-870.

Reising, S. C., U. S. Inan, and T. F. Bell (1999), ELF sferic energy as a proxy indicator for sprite occurrence, Geophys. Res. Lett., 26, 987-990.

Rodger, C. J., M. Cho, M. A. Clilverd, and M. J. Rycroft (2001), Lower ionospheric modification by lightning-EMP: Simulation of the night ionosphere over the United States, Geophys. Res. Lett., 28, 199-202.

Rycroft, M. J. (1973), Enhanced energetic electron intensities at $100 \mathrm{~km}$ altitude and a whistler propagating through the plasmasphere, Planet. Space Sci., 21, 239-251.

Rycroft, M. J., and R. G. Harrison (2012), Electromagnetic atmosphereplasma coupling: The global atmospheric electric circuit, Space Sci. Rev., 168, 363-384, doi:10.1007/s11214-011-9830-8.

Sauvaud, J. A., T. Moreau, R. Maggiolo, J. P. Treilhou, C. Jacquey, A. Cros, J. Coutelier, J. Rouzaud, E. Penou, and M. Gangloff (2006), High energy electron detection onboard DEMETER: The IDP spectrometer, description and first results on the inner belt, Planet. Space Sci., 54(5), 502-511.

Smith, R. L., and J. J. Angerami (1968), Magnetospheric properties deduce from OGO 1 observations of ducted and non-ducted whistlers, J. Geophys. Res., 73, 1-20, doi:10.1029/JA073i001p00001.

Soula, S., O. van der Velde, J. Montanyà, T. Neubert, O. Chanrion, and M. Ganot (2009), Analysis of thunderstorm and lightning activity associated with sprites observed during the EuroSprite campaigns: Two case studies, Atmos. Res., 91, 514-528, doi:10.1016/j.atmosres.2008.06.017.

Strangeways, H. J. (1999), Lightning induced enhancements of D-region ionisation and whistler ducts, J. Atmos. Sol. Terr. Phys., 61, 1067-1080.

Voss, H. D., et al. (1984), Lightning-induced electron precipitation, Nature, 312, 740-742, doi:10.1038/312740a0.

Voss, H. D., M. Walt, W. L. Imhof, J. Mobilia, and U. S. Inan (1998), Satellite observations of lightning-induced electron precipitation, J. Geophys. Res., 103, 11,725-11,744. 